\title{
History and Political Economy in Karl Marx's Mathematical Manuscripts
}

\author{
Agamenon R. E. Oliveira \\ Polytechnic School of Rio de Janeiro, Rio de Janeiro, Brazil \\ Email: agamenon.oliveira@globo.com
}

How to cite this paper: Oliveira, A. R. E. (2021). History and Political Economy in Karl Marx's Mathematical Manuscripts. Advances in Historical Studies, 10, 176-190. https://doi.org/10.4236/ahs.2021.103011

Received: July 6, 2021

Accepted: August 27, 2021

Published: August 30, 2021

Copyright $\odot 2021$ by author(s) and Scientific Research Publishing Inc. This work is licensed under the Creative Commons Attribution International License (CC BY 4.0).

http://creativecommons.org/licenses/by/4.0/

\begin{abstract}
Even during the period when Marx was completely involved with the analysis of the capitalist mode of production in order to study its laws of internal development, he meticulously followed the progress of the natural sciences. Encouraged by these studies, he also made several inroads in mathematics, paying special attention to differential and integral calculus, considering its logical and philosophical foundations. These studies had begun many years previously, but intensified in $1865 / 1866$, as they were intended to build solid theoretical support for his studies of political economy.
\end{abstract}

\section{Keywords}

Mathematics in Marx, Marx and the Natural Sciences, Marx and Philosophy

\section{Introduction}

Marx (1818-1883) and Engels' (1820-1895) interest in the natural sciences can be seen in a series of texts, scattered quotes, and their voluminous correspondence ${ }^{1}$. In the preface to the second edition of Anti-Dühring, one reads:

Marx and I were undoubtedly almost the only ones to retain the conscious dialectic of German idealist philosophy in our materialist conception of nature and history. However, in order to conceive nature in a dialectical and at the same time materialistic way, it is necessary to know mathematics and the natural sciences. Marx was a profound mathematician, but we could not study the natural sciences except in a fragmentary, discontinuous and sporadic way... And further on: Nature is governed by the same dialectical laws of the movement and

${ }^{1}$ In the correspondence exchanged between Marx and Engels, the following are of importance: Marx to Engels in January 11, 1858, May 20, 1865, July 6, 1863 and August 25, 1879; Engels to Marx in August 18, 1881 and November 21, 1882; Marx's response on November 22, 1882 (Marx, 1955) contains interesting discussions about the natural sciences or mathematics. 
which also dominate history, in apparent succession of events... (Engels, 1971). This unified view that Marx and Engels have of nature, society and the ways in which thought apprehends external reality, is not unanimity among Marxists ${ }^{2}$.

In this study, we will deal exclusively with Marx's mathematical manuscripts, with the purpose of making this field better know, in relation to which Marx left about 1000 pages of manuscripts. Second, we would like to emphasize the breadth and depth of the studies carried out by Marx on which to base his new political economy. As we will see later, his studies on infinitesimal calculus did not have an immediate application to political economy, but they were important in helping him raise a series of problems pertaining to economics, which almost half a century later, with the development of new tools mathematics, were taken up and fully developed.

We will use the text translated by Professor S. A. Yanovskaya, published in Moscow in 1968, with the title Mathematicheskie Rukopsii. It contains Marx's first mathematical writings in their original form in Russian translation. They appeared in 1933, on the occasion of the fiftieth anniversary of Marx's death (Kol'man, 1983).

Specifically in relation to Marx's mathematical studies, despite previous studies, on July 6, 1863, he wrote to Engels:

In my spare time, I work with differential and integral calculus. By the way, I have too many books on the subject and I will send one to you if you want to study this topic. I consider it indispensable for your military studies. Thus, this subject is the easier part of mathematics (involving mere technique) than higher algebra. Outside the knowledge of usual algebra and trigonometry, there is nothing more necessary to study, except for a general purpose with the conic sections.

\section{Structure of Mathematical Manuscripts}

The basic structure of the manuscripts left by Marx, apart from a few subdivisions, is as follows:

- Two Manuscripts on Differential Calculus.

1) On the Concept of Derived Function;

2) About Differential.

- Sketches and Supplements for the study "About Differential".

- About the History of Differential Calculus.

- Taylor and McLaurin theorems and the Lagrange Theory of Derived Func${ }^{2}$ Gyorgy Lukács (1885-1971), in a footnote to his famous book History and Class Consciousness (Lukács, 1975), states: This limitation of the method to social-historical reality is very important. The mistakes resulting from the Engelsian exposition of the dialectic are essentially due to the fact that Engels - following Hegel's bad example-extends the dialectical method also to the knowledge of nature. However, the decisive determinations of dialectics-interaction of subject and object, unity between theory and practice, historical transformation of the categories substrate as the basis for their transformation in thought, etc.-do not occur in the knowledge of nature. Unfortunately, on these pages I do not have the possibility to discuss this issue in detail. Later, Lukács changed his mind about the application of dialectics in nature. 
tions.

- Appendices of the Manuscript “On the History of Differential Calculus”.

\section{General Considerations on the Manuscripts}

First, the relationship between mathematics and dialectical materialism, which was Marx's fundamental motivation, shed lights on two closely associated problems. The first, it is need to philosophically generalize the results of mathematics to incorporate them into the conceptual framework of science. Second, the methods of dialectical materialism had to illuminate and point out solutions to the problems and difficulties of mathematics, in turn enriching the dialectical method itself. These results, Marx believed, could be used in the preparation of his major work: Capital.

Marx also had practical reasons for these mathematical studies: given the insufficiency that appeared in the classical economics of Adam Smith (1723-1790) and David Ricardo (1772-1823) in terms of correctly describing the dynamics of capitalist economics, he set out to overcome this weakness; however, this task would only be possible through philosophical thought ${ }^{3}$. Marx repeatedly stated that the extremely complex nature of capitalist economics made it impossible to establish comparative schemes with other sciences such as biology or physics. However, he considered that the application of mathematics was not only viable but very fruitful. This actually happened and was confirmed when Marx built a new conceptual basis for his political economy with the use of mathematics, without the infinitesimal calculation being directly applied to his major work ${ }^{4}$. In this way, a series of new economic concepts were created, such as the concepts of value, greatly enriched with new categories such as abstract work, concrete work, organic composition of capital, differential income, etc.

Another application of mathematics to economics that Marx envisioned was that of statistics. He knew that the large-scale mechanisms and processes that occur in the economy had methodological significance for statistics itself, as he himself stated:

The value of commodities as determined by labor time is only their average value. This average appears as an external abstraction if it is calculated out

\footnotetext{
${ }^{3}$ Engels, in the preface to the second edition of the second volume of Capital, develops an interesting analogy between the discovery of Marx's theory of surplus value and the end of the Lavoisier's theory of phlogistics. According to Engels, Marx is for Lavoisier (1743-1794) as Adam Smith and David Ricardo were for Priestley (1733-1804) and Scheele (1742-1786). These last two scientists, even having isolated the oxygen, but only Lavoisier would discover the fundamental role of this chemical element in combustion, casting aside the belief in the existence of such a substance called phlogiston (Marx, 1970a).

${ }^{4}$ Here it is worth making an analogy between the situation of Marx in view of a possible application of infinitesimal calculus to economics and that of Newton who invented, together with Leibniz, differential and integral calculus and also did not use it directly in mechanics. Marx makes an in-depth study of calculus as a way of giving more solid conceptual support to his studies of economics. Newton, on the other hand, even though he developed calculus and elaborated the theory of motion, did not use it, despite the immense possibilities of its use in mechanics. Only after Euler, around 1750, developed the differential form of Newton's second law would a mechanics based on calculus appear. This process culminated in the highly formalized and mathematicized Analytica
} 
as an average figure of an epoch, e.g., a pound of coffee is one shilling if the average price of coffee is taken over, let us say, 25 years; but it is very real if it is at the same time recognized as the driving force and the moving principle of the oscillations which commodity prices run through during a given epoch. This reality is not merely of theoretical importance: it forms the basis of mercantile speculation, whose calculus of probabilities depends both on the median price averages peaks and average troughs of oscillation above or below this center (Marx, 1973).

Marx studied several textbooks on differential calculus. He used many other books from University of Cambridge courses, the same University where Newton (1642-1727), in the seventeenth century, held a chair in mathematics, whose traditions continued until Marx's day. Among the books he studied were Abbot Sauri (1741-1785): Full Mathematics Course (1776), based on Leibniz's methods (1646-1716) and written with his notation; also Newton's book: Unlimited Number of Terms of the Analysis of the Equations (1669). In addition to these cited books, Marx also used the English translation of the French text by J. L. Boucherlat (1775-1848): Elements of Differential and Integral Course (1852). This text combined the ideas of D'Alembert (1717-1783) and Lagrange (1736-1813). Marx also studied the texts of Euler (1707-1783) and McLaurin (1698-1746) which popularized Newton's works.

It is known that Marx was primarily interested in the views of Lagrange who identified the difficulties of differential calculus, being interested in the means of converting calculus into an algebraic procedure, rejecting Newton's vague ideas about the concepts of "infinitely small" and "limit". Marx then began to work on his own methods of explaining calculus without these inconsistencies. The path he chose was a return to algebra with a complete understanding of the algebraic roots of differential calculus ${ }^{5}$.

\section{The Core of the Questions Studied by Marx}

Although Marx had a critical view of Lagrange's work, as we will see later, he identified more with his method. Thus, Marx studied the multiple roots theorem of an algebraic equation, because of its close relationship with the successive differentiations of the equations. This issue was addressed by Marx in a series of manuscripts and also appears in the manuscripts now studied. He gave these the titles of Algebra I and Algebra II. Marx also devoted special attention to the theorems of Taylor (1685-1731) and McLaurin.

The agreement he had with Lagrange did not prevent him from criticizing him for not realizing the dialectical character of his developments. In this way, Marx rejected both aspects of mathematical analysis. Pure analytical reduction and pure and simple introduction of the new into mathematics from the outside, was one of the Hegel's characteristics (1770-1831).

According to E. Kol'man, the first part of the third chapter of the manuscript, ${ }^{5}$ See Lagrange Theory of Analytical Functions (Lagrange, 1881). 
whose title is The Historical Development of Differential Calculus, contains a summary of the methods of Newton, Leibniz, D'Alembert and Lagrange. In the second part, which summarizes the first, there are three sections with the following headings: 1) Mystified Differential Calculation; 2) Rational Differential Calculation; 3) Purely Algebraic Differential Calculus.

What seems clear from this part of Marx's work referred to by Kol'man is that he, like Hegel, considered all efforts to provide a logical-formal foundation for mathematical analysis to be valid. In this way, he set himself the task of developing this foundation, as he understood that this was the role of dialectical analysis and that it united historical and logical aspects.

The fundamental questions which Marx discusses in his manuscripts are the same ones that have permeated many of the debates that have taken place since the origin of differential calculus itself. They revolve mainly around the philosophical difficulties and ambiguities that arise in the analysis of infinitesimal elements, sometimes null, sometimes immeasurable. These problems also clashed with geometric intuition, a privileged form and method of analysis that is still hegemonic among mathematicians, not by chance called geometers.

Faced with these difficulties, mathematicians were divided into schools with different views on how to solve them. The English school at Berkeley (1685-1753), McLaurin, Taylor, Simpson (1710-1761), Landen (1719-1790), etc., tend to clarify these notions by adopting Newton's method of fluxions ${ }^{6}$ as the way forward. The continental school was characterized by the tendency to associate the differential calculus with the idea of function, with an emphasis on an Eulerian vision ${ }^{7}$.

The ease of Leibniz's notation and the effectiveness of his algorithms greatly favored the path indicated by Euler and gave differential calculus an almost automatic impulse, although this school often appealed to philosophy in order to justify the notion of infinitely small ${ }^{8}$.

It was only in the first decades of the nineteenth century that the French mathematician Augustin-Louis Cauchy (1789-1857) introduced the necessary rigor that was lacking in the fundamentals of infinitesimal calculus. He did this through three fundamental works, launched between 1821 and 1829: Analysis Course (1821), Summary of Classrooms on Infinitesimal Calculus (1823), and Classrooms of Differential Calculus (1829). In these studies the concept of limit was the fundamental question. ${ }^{9}$ His definition, taking up the idea of D'Alembert, definitively broke with the still underlying geometric concept and made the limit an arithmetic concept.

\footnotetext{
${ }^{6}$ The so-called fluxions method is Newton's most famous approach to infinitesimal calculus. In it, mathematical quantities are considered to be engendered by a continuous increase, similar to the space that describes a moving body. In this way, variations in those quantities are equivalent to the speed of the movements that engender them. These speeds are called fluxions (Newton, 1994).

${ }^{7}$ See: Institutiones calculi differentialis (1755) and Institutionum calculi integralis (1768-1770) (Oliveira, 2007).

${ }^{8}$ See the chapter Leibniz and the Sciences of Engineering, in the book The Dialogue between Sciences, Philosophy and Engineering, published in England, College Publications, London, 2017.

${ }^{9}$ We have no record of Marx's reading Cauchy's works.
} 


\section{Analysis of the Manuscripts}

- Two Manuscripts on Differential Calculus

In this first part, the manuscripts are subdivided into two sections: 1) On the Concept of Derived Function and 2) On Differential, Marx simply intends to show the process of function differentiation, starting with simple polynomial functions where he mainly emphasizes the processes of passing to the limit, which he sometimes calls disappearances. In 1), Marx uses functions of a single independent variable. In 2), for the differentiation process to become more general, he makes use of functions with more than one variable, albeit dependent on a single independent variable.

1) In this first item, Marx shows the development and derivation process of polynomial functions starting with the simplest possible $y=a x$. Establishing the variations for the independent variables from $x$ to $x_{1}$ and the dependent variables from $y$ to $y_{1}$ and obviously small variations around $x$ and $y$, Marx shows the ratio between finite differences as:

$$
\Delta y / \Delta x=y_{1}-y / x_{1}-x=a
$$

where ais the limit of the constant ratio.

Marx emphasizes that nothing occurs on the right side of the equation and that the derivation process only occurs on the left side. When making the transition to the limit a remains unchanged. After crossing the limit, we will have $\mathrm{d} x / \mathrm{d} y=0$ and it is believed that both $\mathrm{d} y$ and $\mathrm{d} x$ are very small or infinitely small quantities.

Continuing his analysis, Marx increases the degree of the polynomial function so that the higher order derivatives can emerge beyond the first order derivative, depending on the degree of the polynomial. Thus, he takes $y=a x^{3}+b x^{2}+c x+e$.

The reason between the finite differences is written as follows:

$$
\Delta y / \Delta x=a\left(x_{1}^{2}+x_{1} x+x^{2}\right)+b\left(x_{1}+x\right)+2
$$

The derivation process leads to the following:

$$
0 / 0=\mathrm{d} y / \mathrm{d} x=3 a x^{2}+2 b x+c
$$

For this type of function, the symbols $\mathrm{d} y / \mathrm{d} x, \mathrm{~d}^{2} y / \mathrm{d} x^{2}$, etc., appear, according to Marx, as a genealogical process of derivatives with respect to the original function, with varying degrees of disappearances, that is, of passing to the limit in each derivation.

Marx also shows the derivation processes of the functions $y=a x^{m}$ and $y=\left(a^{2}+x^{2}\right)^{1 / 2}$.

2) In this second item, Marx considers a function $f(x)$ or $y=u z$ the function to be differentiated; $u$ and $z$ are both functions dependent on the independent variable $x$. They are independent variables with respect to the $y$ function, which depends on them and thus on $x$. Establishing the processes of finite differences, we will have:

$$
y_{1}=u_{1} x_{1} \text { and } y_{1}-y / x_{1}-x
$$

or 


$$
\Delta y / \Delta x=z_{1} u_{1}-u / x_{1}-x+u x_{1}-x / x_{1}-x=z_{1} \Delta u / \Delta x+u \Delta z / \Delta x
$$

then

$$
\mathrm{d} y / \mathrm{d} x=z \mathrm{~d} u+u \mathrm{~d} z / \mathrm{d} x
$$

and

$$
\mathrm{d}(u x)=z \mathrm{~d} u+u \mathrm{~d} x \text { which equals } \mathrm{d} y / \mathrm{d} x=z \mathrm{~d} u / \mathrm{d} x+u \mathrm{~d} z / \mathrm{d} x
$$

Or $\mathrm{d} y / \mathrm{d} x=f^{\prime}(x)$, this being the differential form for the equation with only a dependent variable.

Marx examines the corresponding "derivatives" of the differential coefficients $\mathrm{d} u / \mathrm{d} x, \mathrm{~d} z / \mathrm{d} x$ and adds that it is not possible to answer this only with the equation $y=u z$. However, if we replace the arbitrary functions with their relations to the independent variable, they can be calculated. For example, if we have $u=x^{4}$ and $z=x^{3}+a x^{2}$.

Using the previous procedures we arrive at the same previous result, that is: $\mathrm{d} y=f^{\prime}(x) \mathrm{d} x$.

These two manuscripts on differential calculus also have three sketches (drafts) detailing the previous procedures, which we refer to as sketches and supplements in the main structure of the manuscripts. They complement and detail the procedures contained in 1) and 2).

- History of Differential Calculus

First Sketch

In this item, Marx does not exactly present a history of differential calculus, as we might think, situating, dating and contextualizing the main developments of differential calculus. Rather he mainly presents the different ways in which the differential calculations of Newton, Leibniz and D'Alembert operated.

1) Newton. The speeds or fluxions of the variables $x, y$, etc., are called $x^{\prime}, y^{\prime}$, etc. For example, if $u$ and $x$ are variables connected and generated by a continuous movement, then $u^{\prime}$ and $x^{\prime}$ represent their rates of change and then $u^{\prime} / x^{\prime}$ is the reason for this variation in which their increments are generated.

Then Marx shows the operational form of Newton's method for differential calculus. It takes the function $y=u z ; y^{\prime}, u^{\prime}$ and $z^{\prime}$ are the speeds at which $y, u$ and $v$ are varying; then the moments of $y^{\prime}, u^{\prime}$ and $u^{\prime}$ are $\tau y^{\prime}, \tau u^{\prime}$ and $\tau u^{\prime}$, where $\tau$ is the infinitesimal time interval. In this way, one obtains:

$$
y+\tau y^{\prime}=\left(u+\tau u^{\prime}\right)\left(z+\tau z^{\prime}\right)=u z+u \tau z^{\prime}+z \tau u^{\prime}+2 \tau u^{\prime} z^{\prime}
$$

So, we will have: $\tau y^{\prime}=u \tau z^{\prime}+z \tau u^{\prime}+2 \tau u z^{\prime}$

As $\tau$ is infinitesimal it disappears and so does the product $2 \tau u^{\prime} z^{\prime}$. We then have:

$$
y^{\prime}=u^{\prime} z+z^{\prime} u
$$

while the fluxion of the function $y=u z$ is $u^{\prime} z+z^{\prime} u$.

2) Leibniz. Calculation of the differential of the $u z$ function; $u$ becomes $u+\mathrm{d} u$ and $z, z+\mathrm{d} z$, then:

$$
u z+\mathrm{d}(u z)=(u+\mathrm{d} u)(z+\mathrm{d} z)=u z+u \mathrm{~d} z+z \mathrm{~d} u+\mathrm{d} u \mathrm{~d} z \quad \text { we have: }
$$




$$
\mathrm{d}(u z)=u \mathrm{~d} z+z \mathrm{~d} u
$$

3) D'Alembert. The problem is put in general terms.

Let $y=f(x)$; operating with the differences:

$y_{1}-f(x+h)$; determining the value of $y_{1}-y / h$, becomes, when $h$ tends towards 0 , the value $0 / 0$.

After presenting some more developments exercising the operational forms presented, Marx goes on to describe his algebraic method:

Given the function $f(x)$, its first derivative is $f^{\prime}(x)=\Delta y / \Delta x$.

It follows that $\Delta y=f^{\prime}(x) \Delta x$; like $y=f(x)$ and $\Delta y=\Delta f(x)$.

Operating with finite differences, we have: $x_{1}-x=0, y_{1}-y=0$, where we get $\mathrm{d} y / \mathrm{d} x=f^{\prime}(x)$. We can also use $\mathrm{d} y=f^{\prime}(x) \mathrm{d} x, \mathrm{~d}(f(x))=f^{\prime}(x) \mathrm{d} x$ or $\mathrm{d} y=\mathrm{d}(f(x))$.

Second Draft: The Historical Path of Development

This second sketch of the history of differential calculus concentrates a large part of Marx's criticism, while it is also where his purely algebraic differential calculus proposal appears.

1) Mystified Differential Calculus

If $x_{1}=x+\Delta x$ and if we adopt $x_{1}=x+\mathrm{d} x$ or $x+x^{\prime}$, where $\mathrm{d} x$ is admitted as a metaphysical explanation. First, it exists, and only later is it explained.

So, $y_{1}=y+\mathrm{d} y$ or $y_{1}=y+y^{\prime}$. From the arbitrary hypothesis, the consequence that follows within the binomial expansion $x+\Delta x$ or $x+x^{\prime}$, the terms in $x$ and $\Delta x$ that are obtained by adding the first derivative, for example, must be analyzed to obtain the correct result.

As the basis of the differential calculation comes from this last result, called differentials, and is admitted by explanation or hypothesis, then $\mathrm{d} y / \mathrm{d} x$ or $y^{\prime} / x^{\prime}$, the differential symbolic coefficient, are also anticipated by this explanation.

If the increment of $x=\Delta x$ and the increment of the dependent variable is $\Delta y$, then it is self-evident that $\Delta y / \Delta x$ represents the ratio of the increments of $x$ and $y$.

This explains that $\Delta x$ appears in the denominator, which is the increment of the independent variable, not the inverse; while the final result of the differential form, called the differential, is also given in the beginning by the differentials.

It is important to clarify that Marx distinguishes the differentials $\mathrm{d} x$ and $\mathrm{d} y$, the infinitesimals of the differences $\Delta x$ and $\Delta y$, from the differential $\mathrm{d} y=f^{\prime}(x) \mathrm{d} x$.

At this point in the manuscript, Marx then asks his question: why does the mysterious suppression of terms remain in the way? He responds by saying that we admit that we know that they are in the way and that they do not really belong to the derivative. He justifies this by saying that the answer is very simple and that this is found purely by experiment. Experiment, that is to say by calculation because the true derivative has been known for a long time, even for complicated functions of $x$, as well as through its analytical forms such as equations of curves, etc., but also through "the most decisive experiment possible", named 
after the treatment of the simplest algebraic function of the second degree (see Equations (6), (7) and (8)). Let us look at this:

$$
\begin{gathered}
y=x^{2} \\
y+\mathrm{d} y=(x+\mathrm{d} x)^{2}=x^{2}+2 x \mathrm{~d} x+\mathrm{d} x^{2} \\
y+y^{\prime}=\left(x+x^{\prime}\right)^{2}=x^{2}+2 x x^{\prime}+x^{2}
\end{gathered}
$$

If we subtract the original function, $x^{2}\left(y=x^{2}\right)$ from both sides, we have (Equations (9) and (10)):

$$
\begin{gathered}
\mathrm{d} y=2 x \mathrm{~d} x=\mathrm{d} x^{2} \\
y^{\prime}=2 x x^{\prime}+x^{\prime} x
\end{gathered}
$$

Then we delete the last terms on the right, so we have (11) and (12):

$$
\begin{aligned}
\mathrm{d} y & =2 x \mathrm{~d} x \\
y^{\prime} & =2 x x^{\prime}
\end{aligned}
$$

So $\mathrm{d} y / \mathrm{d} x=2 x$ and $y^{\prime} / x^{\prime}=2 x$.

At this point in the manuscript, Marx then asks his question: why the mysterious suppression of terms that remains in the way?

As we could see from the reasoning developed by Marx, his questioning is about the character and explanation of the infinitesimals and their disappearance in the derivation process. He makes no mention of the question of the order of magnitude of these infinitesimals and that the problem is solved through experiment. This term is used to replace the word exact calculation or the exact forms that have been known for a long time.

2) Rational Differential Calculation

D'Alembert begins his method with the starting point of Newton and Leibniz: $x_{1}=x=\mathrm{d} x$. But he immediately makes the fundamental correction $x_{1}=x+\Delta x$, that is, $x$ and an indefinite finite increment that we call $h$. The transformation of $h$ or $\Delta x$ into $\mathrm{d} x$ (like all French scholars at the time he uses Leibniz notation) is found first as the final result of development or at least before, the gate opens while in the mystifying developments of calculus initiators it appears as a point of departure.

The reason for the differences:

$$
[f(x+h)-f(x)] / h=[f(x+h)-f(x)] / x_{1}-x
$$

This is the starting point of its construction.

This difference $f(x+h)-f(x)$ corresponds to a given algebraic function of $x$, and remains so once $x$ is replaced with increments $x+h$ in the original function of $x$, for example $x^{3}$ (Equations (14), (15) and (16)).

$$
\begin{gathered}
f(x)=x^{3} \\
f(x+h)=(x+h)^{3}=x^{3}+3 x^{2} h+h^{3} \\
f(x+h)-f(x)=x^{3}+3 x^{2} h+3 x h^{2}+h^{3}-x^{3}
\end{gathered}
$$


In D'Alembert it is necessary to show this difference because the steps of the development are carried out with it. In place of the positive expression of difference, $f(x+h)-f(x)$ goes to the left side of the equation. And the emphasis on difference, instead of increment (fluxion in Newton), is masked at least in $\mathrm{d} y$ in Leibnizian notation as opposed to Newtonian $y^{\prime}$.

The derivation process in D'Alembert is essentially the same as in Leibniz and Newton, but the $3 x^{2}$ derivative is separated in a strictly algebraic manner in relation to other mathematicians. There is no development but a separation of $f(x+h)$-here $3 x^{2}$-by a factor $h$ and the neighborhood terms separated into parts in the series.

Marx further notes: “D'Alembert stripped the mystical veil of differential calculus and took a huge step forward. In his Traité des fluides ${ }^{10}$ which appeared in 1744, the Leibnizian method continued to prevail for many years in France. It is necessary to note that Newton continued to hold a dominant position in England until the first decades of the nineteenth century. But here, as in France, D'Alembert's initial studies have remained dominant until the present, with some "modifications".

3) Purely Algebraic Differential Calculus

Here Marx refers to the work of Lagrange, Theories of Analytical Functions (1797 and 1813). As in the developments of the previous authors, the starting point is the increment of $x$.

Given the function $y$ or $f(x)$, in the mystified method it will be $y_{1}$ or $f(x+\mathrm{d} x), y_{1}$ or $f(x+h)=f(x+\mathrm{d} x)$ in the rational method. In the binomial type expansion

$$
x^{m}+m x^{m-1} h+\text { etc. }
$$

this second term $m x^{m-1} h$ has already provided the true differential coefficient sought.

a) When $x+h$ replaces $x$ in a given original function of $x, f(x+h)$ is related to a series expansion.

Example:

$$
(x+h)^{3}=x^{3}+3 x^{2} h+\text { etc. }
$$

D'Alembert's method simply algebraized $(x+\mathrm{d} x)$ or $\left(x+x^{\prime}\right)$ in $(x+h)$ and thus $f(x+h)$ of $y+\mathrm{d} y, y+y^{\prime}$ in $f^{\prime}(x+h)$. Lagrange reduced the entire expression to one of a purely algebraic character, putting it in a more general form.

b) In the first method presented in 1) and named by Marx as mystified differential calculus, as well as in the rational method in 2), the true coefficient sought is manufactured through the binomial theorem. The other coefficients are also obtained by the binomial expansion. The complete problem is then solved by finding the algebraic methods for the development of all sorts of func${ }^{10}$ Indeed, the full title of D'Alembert's work is Traité de lequilibre et du mouvement des fluides (1744) as a continuation of his Traité de dynamique published the previous year. In 1752, D'Alembert published Essay d une nouvelle théorie des resistances des fluids, following which hydrodynamics became a branch of mechanics (D’Alembert, 1968). 
tions of $x+h$ in the form of powers of $h$. So far there is nothing in Lagrange that could not be obtained directly from D'Alembert.

c) While until now the development of $y_{1}$, or $f(x+h)$, etc., follows these steps in place of traditional differential calculus and clarifies the mystery of the preceding methods, if

$$
y+\mathrm{d} y \text { or } y+y^{\prime}, x+\mathrm{d} x \text { or } x+x^{\prime}
$$

is used, they follow the application of the binomial theorem, representing from the beginning the increments of $x_{1}$ as $x+\mathrm{d} x$, the increase of $y_{1}$ as $y+\mathrm{d} y$, and thus, transform the monomial into a binomial. Having the form $f(x+h)$ and making the derivative algebraically, valid for all functions of any power of $x$, in a series expansion.

What Lagrange does, starting from this point, is to algebraize the differential calculus, using Taylor's theorem, described by Newton and the Newtonians.

So:

$$
f(x+h)=y
$$

or

$$
f(x+h)=f(x)+\mathrm{d} y / \mathrm{d} x h+\mathrm{d}^{2} y / \mathrm{d} x^{2} h^{2} / 2 !+\mathrm{d}^{3} y / \mathrm{d} x^{3} h^{2} / 3 !+\text { etc. }
$$

- Taylor and McLaurin theorems and the Lagrange Theory of Derived Functions

I) Marx observes that Newton's discovery of the binomial theorem revolutionized all algebra, as it made possible a general theory of equations, even though it is only a basis for differential calculus. He adds that although textbooks prove that the binomial theorem can be deduced from Taylor and McLaurin's theorems and vice versa, it is important to note that it was Lagrange in his theory of derived functions that provided a new foundation for differential calculus.

Taylor's theorem historically predates McLaurin's and they provide, under certain conditions, for any function of $x$ that varies by means of positive or negative additions $h$, a series of symbolic expressions, indicating how such functions, whose solutions although they can be quite algebraically complicated, can be easily found through differential calculus.

Taylor's formula is the following:

$$
y_{1}=y+\mathrm{d} y / \mathrm{d} x h+\mathrm{d}^{2} y / \mathrm{d} x^{2} h^{2} / 2 !+\mathrm{d}^{3} y / \mathrm{d} x^{3} h^{2} / 3 !+\cdots
$$

McLaurin's formula is (Equation (18))

$$
\begin{gathered}
f(x) \text { or } \\
y=(y)_{0}+\mathrm{d} y / \mathrm{d} x x / 1+\mathrm{d}^{2} y / \mathrm{d} x^{2} x^{2} / 2 !+\mathrm{d}^{3} y / \mathrm{d} x^{3} x^{2} / 3 !+\cdots
\end{gathered}
$$

II) McLaurin's theorem can be treated as a special case of Taylor's theorem.

$$
\begin{gathered}
y+f(x) \\
y_{1}=f(x+h)-f(x) \text { or } \\
y+\mathrm{d} y / \mathrm{d} x h+1 / 2 ! \mathrm{d}^{2} y / \mathrm{d} x^{2} h^{2}+\text { etc. }+1 / n ! \mathrm{d}^{n} y / \mathrm{d} x^{n} h^{n}+\text { etc. }
\end{gathered}
$$

Placing $x=0$ in $f(x+h), f(x)$ and on the right side of the equation, we 
have (Equations (19), (20) and (21)):

$$
\begin{gathered}
f(h)=y+(\mathrm{d} y / \mathrm{d} x) h+\mathrm{d}^{2} y / \mathrm{d} x^{2} h^{2} / 2 !+\mathrm{d}^{3} y / \mathrm{d} x^{3} h^{2} / 3 !+\text { etc. } \\
y_{1}=f(x+h)=f(0+h) \\
f(x)=y \text { or } \\
f(0)+\mathrm{d} y / \mathrm{d} x x+\mathrm{d}^{2} y / \mathrm{d} x^{2} x^{2} / 2 !+\mathrm{d}^{3} y / \mathrm{d} x^{3} x^{2} / 3 !+\text { etc. }+\mathrm{d}^{n} y / \mathrm{d} x^{n} x^{n} / n !+\text { etc. } \\
f(x)=f(0)+f^{\prime}(0) x+f^{\prime \prime}(0) x^{2} / 2 !+f^{\prime \prime \prime}(0) x^{3} / 3 !+\text { etc. }
\end{gathered}
$$

III) Lagrange's Theory of Functions

Lagrange uses the algebraic basis of Taylor's theorem and thus operates with the more general formula of differential calculus. Starting with Taylor's equation:

$$
\begin{gathered}
y_{1} \text { or } f(x+h)=y \text { or } \\
f(x)+A h+B h^{2}+C h^{3}+\text { etc. }
\end{gathered}
$$

According to Marx, there are problems in this development. $F(x+h)$ does not always have a binomial form of a definite degree, having an indefinite form in general of any function of $x$. Lagrange's contribution was to formulate a rationale based on algebraic analysis for Taylor's theorem and differential calculus in general.

Lagrange provided a purely algebraic development for all possible functions of $f(x+h)$ with positive powers of $h$ and then gives it the name of differential calculus.

Lagrange managed to get rid of all metaphysical transcendence, as in the calculation of Newton's fluxions and the infinitesimals of different orders from Leibniz, the limit value theorem of the nulling quantities and the replacement of $0 / 0$ by $(\mathrm{d} y / \mathrm{d} x)$ as symbol for the differential coefficient.

Appendices to the "On the History of Calculus" Manuscript

This part of the manuscript has three parts:

a) On the ambiguity of the terms "limit" and "limit value"

Here Marx points out that the "limit value" of series development of increments becomes the "limit value" of development where they are usually algebraic values or have an arithmetic meaning. Marx emphasizes that the "limit value" can be misinterpreted and actually is constantly misinterpreted.

b) Comparison between D'Alembert's method and the algebraic method

Marx again shows that D'Alembert starts with $(x+\mathrm{d} x)$, but corrects the expression for $(x+\Delta x)$ and $(x+h)$; a development in the series which becomes necessary when $\Delta x$ or $h$ is transformed into $\mathrm{d} x$, but the whole development really takes place. The problem then consists in decoupling the initial form, the function $f(x)$, from its factor $h$ and from its other neighboring terms.

c) Analysis of D'Alembert's method through yet another example

Marx presents in its general lines the method of D'Alembert, distinguishing it from that of Lagrange, in which the differential expression also acts in the symbolic part; with it the derivation does not represent the algebraically differentia- 
tion but instead derives the functions algebraically and directly from the binomial or simply accepts its differential form "by symmetry", since it is known from the differential calculation that the first derivative is $\mathrm{d} y / \mathrm{d} x$, the second $\mathrm{d}^{2} y / \mathrm{d} x^{2}$, etc.

\section{Marx's Precursor of Mathematical Political Economy}

As we saw earlier, Marx did not directly apply his developments in differential and integral calculus to the studies of political economy, which resulted in his masterpiece: Capital. However, Marx fertilized the application of mathematics to political economy, not calculus, but mathematics that had not yet been discovered, as is the case with linear algebra. For this, Marx developed, and in some cases only raised, this application in a series of problems as we intend to show in this item. Professor João Damásio's study, Mathematics and the Critique of Political Economy, and a chapter from the book Science, Philosophy and Politics, published in 2013 by EDUFBA and coordinated by Olival Freire Júnior and Saulo Carneiro, give a series of examples of this transition between the concepts developed by Marx for certain problems and their future development with new mathematics. We will use this excellent article to exemplify this evolution that comes out of Marx and goes to the full development and solution of some of these problems:

1) The question of duality

In the first chapter of Book I of Capital (Marx, 1970a), Marx discusses the dual character of the commodity with a high level of abstraction. The difference between "use values" and "exchange values" shows an important part of this effort to apprehend the commodity production system. Today, following the discovery of new fields of mathematics after Marx's death, we know that the vectors of "use values" (physical quantity of goods) and "exchange values" (alternatively "values" or "production prices") and which support "market prices" can be calculated in the form of eigenvectors, as a solution to dual problems formulated on the same physical technological matrix of production.

2) Composition of the value of capital

In Book II of Capital (Marx, 1970b), Marx dedicates the first two sections to the heterogeneity of the compositions of capital in the different branches of industry and establishes the concept of "organic composition of capital", which starts to be used as an instrument to study the different behaviors of industrial capital within the set of "global capital". Using this concept, Marx preceded by many decades of orthodox economic analysis that renamed this relationship the "capital/labor ratio" and started to use it to parameterize mathematical economic models.

3) Open and closed economies

${ }^{11}$ The Physiocratic School emerged in France in the 18th century, in which François Quesnay (1694-1774) was its best known figure. In general, its program aimed to create more favorable conditions for the development of French agriculture and demanded the removal of all the difficulties the latter faced and advocated a rationalization of agriculture along the lines of English agriculture. It was opposed to mercantilism and defended so-called liberal positions in agriculture. 
Marx was one of the first economists to study the question of so-called closed or open economies from the point of view of their capacity for self-sustainability. Contemporary economic models address this issue by guaranteeing the semipositivity of the vector of the net product of the economy. The notion of interdependent commodity production originated in the physiocratic economic school ${ }^{11}$, but was refined and reworked by Marx in Book II of Capital.

4) Simple and extended reproduction

In Section VII of Book I and then in Section III of Book II of Capital, Marx presents the concept of "Simple Reproduction", noting that although it does not exist in real capitalist economies, it nevertheless establishes the preconditions and requirements for understanding "Scale-Up Reproduction" in self-sustaining economies and which results in capital accumulation. It was the first growth model scheme in the history of economic thought. Only in the 1950s did orthodox economic theory mathematically elaborate models for both sectors.

\section{Final Comments and Conclusion}

In his time in Paris during the winter of 1691-1692, Jean Bernoulli (1667-1748) initiated the Marquis de L 'Hôpital (1661-1704) in Leibniz's calculations. Based on these lessons, the Marquis would write the first treatise on differential calculus, published in Paris at the end of June 1696 with the title: Analysis of Infinitely Small Ones for the Intelligence of Curved Lines (L'Hôpital, 1696). The Marquis in a letter addressed to Jean Bernoulli, dated June 15, 1696, left to others the task of developing and writing about integral calculus.

In this inaugural work the infinitely small amounts of the variables $x, y$, and $z$ are defined as $\mathrm{d} x, \mathrm{~d} y$ and $\mathrm{d} z$. Marx denied the existence of these quantities and calls the differential calculus based on Newton's and Leibniz's mystified differential calculus. The trajectory followed by Marx to escape this difficulty goes through the rationalist method of D'Alembert and Euler, ending with the strictly algebraic method of Lagrange, as we have already noted.

Marx's criticism of the mystified method means that these quantities, derivatives and differentials, are not entities or substances of metaphysical type, but exist on their own as symbols and operations having been defined operatively. The method used by Marx is independent of the continuity and limit considerations that characterize the functions of real variables. His method also strengthens his arguments against the metaphysical-mystical interpretation of the dialectical law of negation and is in perfect agreement with the view he shared with Engels regarding the dialectic of nature and the natural sciences ${ }^{12}$.

Marx's mathematical manuscripts clearly show a methodology to guide his view

\footnotetext{
${ }^{12}$ To better characterize the law of negation of negation, we will use a quote from the Brazilian philosopher Leandro Konder (1936-2014), taken from his work on dialectics. He states: The third law takes into account the fact that the general movement of reality makes sense, that is, it is not absurd, it does not end in irrational, unintelligible contradictions, nor is it lost in the eternal repetition of the conflict between theses and antitheses, between affirmation and denial. Affirmation necessarily breeds its negation, but negation does not prevail as such: both affirmation and negation are overcome and what ends up prevailing is a synthesis, it is the negation of negation (Konder, 1981).
} 
of the relationship between science and philosophy. The developments undertaken by him in the field of differential calculus also have a general philosophical purpose. He considered that an advance in the fundamentals of differential calculus also provided advances in the dialectic itself with important implications and repercussions for the analysis of political economy.

\section{Conflicts of Interest}

The author declares no conflicts of interest regarding the publication of this paper.

\section{References}

D’Alembert, J. R. (1968). Traité de l'Équilibre et du Mouvement des Fluides: To Serve as a Suite du Traité de Dynamique. The Library University of Keele.

Engels, F. (1971). Anti-Duhring. Aphrodite Editions.

Kol'man, E. (1983). Karl Marx and Mathematics: On the Mathematical Manuscripts. New Park Publications.

Konder, L. (1981). What Are Dialectics (25th ed.). Editora Brasiliense.

L'Hôpital, M. (1696). Analyse des Infinement Petits Pour l'Intelligenge des Lignes Courbes. Imprimerie Royale.

Lagrange, J. J. (1881). Theorie des fonctions analytiques, Paris, 1813. Oeuvres Lagrange, $I X, 75,76,99,154-155,172$.

Lukács, G. (1975). History and Class Consciousness (2nd ed.). Editorial Grijalbo.

Marx, K. (1970a). Capital, Book 1: The Capitalist Production Process. Editora Civilização Brasileira.

Marx, K. (1970b). Capital, Book 2: The Capital Circulation Process. Editora Civilização Brasileira.

Marx, K., \& Engels, F. (1955). Selected Correspondence. Progress Publishers.

Marx, K., (1973). Grundrisse: Foundations of the Critique of Political Economy (p. 137). M. Nicolaus, Trans., Penguin Books.

Newton, I. (1994). La Méthode des Fluxions et des Suites Infinies. Albert Blanchard.

Oliveira, A. R. E. (2007). Euler's Contribution to Classical Mechanics (12th ed.). IFToMM World Congress. 